\title{
Correlation between Systemic Arterial Hypertension and Bone Morphogenetic Protein-2 in Central Obese Non-Diabetic Men with Evidence of Coronary Artery Calcification
}

\author{
Antonia Anna Lukito ${ }^{1,2 *}$, Allen Widyasanto ${ }^{1,2}$, Trilis Yulianti' ${ }^{1}$, Rusli Muljadii,2, \\ Andi Wijaya ${ }^{1}$, Peter Kabo', Syakib Bakri ${ }^{1}$
}

${ }^{1}$ Post Graduate Program in Clinical Biochemistry, Hasanuddin University, Jl. Perintis Kemerdekaan Km.10. Makassar, Indonesia

${ }^{2}$ Siloam Hospital, Medical School Pelita Harapan University, Jl. Boulevard Jend. Sudirman, Lippo Karawaci, Tangerang 15811, Indonesia *Correspondence: lukito_ant@yahoo.co.id

\section{Abstract}

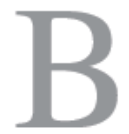

ACKGROUND: Previous studies have confirmed separately the relationships between obesity, insulin-resistance, hypertension and bone morphogenetic protein-2 (BMP-2) with coronary artery calcification, a parameter of subclinical atherosclerosis. It was also reported that BMPs may function as proinflammatory, prohypertensive and proatherogenic mediators. The study aimed to assess the correlation between systemic hypertension and BMP-2 plasma concentration in central-obese non-diabetic men with evidence of coronary artery calcification.

METHODS: This was a cross sectional study on 60 central-obese non-diabetic men, of an average age of 55.2 years, with evidence of coronary calcification, who came for health check-up and met the inclusion criteria consecutively as defined by waist circumference $>90$ $\mathrm{cm}$ and fasting blood glucose $<126 \mathrm{mg} / \mathrm{dL}$. Coronary calcification was defined by coronary artery calcium (CAC) score $\geq 10$ Agatston-unit using Dual Source 64 slice CT scan.

RESULTS: There is positive correlation between hypertension and BMP-2 in central-obese non-diabetic men with evidence of coronary artery calcification. BMP-2 plasma concentration was higher in the hypertensive subjects. The correlation was stronger in younger $(<55$ years old) subjects and subjects with insulin-resistance.

KEYWORDS: Hypertension, BMP-2, Coronary Calcification, Central-Obesity, Age, Insulin-resistance

Indones Biomed J 2011; 3 (3): 185-190

\section{Introduction}

National prevalence of central obesity was $18.8 \%$ according to Indonesia Basic Health Research 2007. Obesity and associated diseases are a major health problem and a major cause of insulin resistance state. Insulin resistance has been found to accelerate atherosclerosis, inflammation, the onset of diabetes, cardiovascular disease, obesity, hypertension, chronic kidney disease, dyslipidemia and coronary calcification $(1,2)$.

Previous studies have confirmed separately the relationships between obesity, insulin resistance, hypertension and bone morphogenetic protein-2 (BMP-2) with coronary artery calcification, a parameter of subclinical atherosclerosis (1, 3-9).

BMP-2, a transforming growth factor-beta super family member cytokine is expressed by both endothelial and vascular smooth muscle cells and regulates a number of cellular processes involved in atherogenesis, including vascular calcification and endothelial activation $(10,11)$ 
Csiszar et al proposed that vascular BMP-2 expression can be regulated by $\mathrm{H}_{2} \mathrm{O}_{2}$-mediated activation of NF-kB both by inflammatory stimuli and by high intravascular pressure. Although high pressure upregulated of NF-kB, it appeared that it directly regulated BMP-2 expression because upregulation of BMP-2 was also observed in vessels of of NF-kB knockout mice (12). Furthermore, numerous evidences suggest that BMPs may function as proinflammatory, prohypertensive, and proatherogenic mediators in the vessel wall (10). However, the correlation between BMP-2 and systemic arterial hypertension remains unclear.

In this study, we examined the correlation between systemic arterial hypertension and BMP-2 plasma concentration in central obese non diabetic men with evidence of coronary artery calcification.

\section{Methods}

This was a cross-sectional study. The study subjects were 60 central obese non-diabetic men with evidence of coronary calcification aged 45-70 years old who came to our hospital for health check-up and met the inclusion criteria consecutively, defined by waist circumference $>$ $90 \mathrm{~cm}$ and fasting blood glucose $<126 \mathrm{mg} / \mathrm{dL}$. Coronary calcification was defined by abnormal coronary artery calcium (CAC) score $\geq 10$ Agatston unit $(13,14)$ using Dual Source 64 slice CT scan analysis. Insulin resistance is a state in which a given concentration of insulin produces a less-than-expected biological effect; HOMAIR has been widely utilized as insulin resistance index in clinical and epidemiological studies. HOMA-IR is calculated according to the formula: fasting insulin $(\mu \mathrm{U} / \mathrm{L})$ $x$ fasting glucose $(\mathrm{nmol} / \mathrm{L}) / 22.5$. There is no standard value for HOMA-IR and the cutoff points of HOMAIR differ among races. Therefore, in this study, Insulin resistance was defined with HOMA-IR $\geq 2.70$ using the median value (HOMA-IR values ranging from 0.46 to 6.42 ) of 60 central obese non-diabetic men, and used it as a cutoff point to differentiate insulin sensitive and insulin resistance subjects. BMP-2 (IBL, USA) were assessed by ELISA. Diagnosis of hypertension was based on JNC-7 guideline.
Statistical analysis was done using SPSS software for Windows version 15.0 with significance level at $\mathrm{p}<0.05$. The bivariate correlation was assessed by Spearman's Rho test. Comparison of BMP-2 between groups were analyzed using Mann-Whitney U test. Non parametric partial correlation was tested using Spearman analysis.

\section{Results}

The average subjects' age was 55.2 years and average waist circumference was $101 \mathrm{~cm}$. Hypertension was found in $36(60 \%)$ subjects, including $30(50 \%)$ subjects having a history of hypertension, $25(41.7 \%)$ subjects taking anti-hypertensive medication and $30(40 \%)$ subjects with $\mathrm{SBP} \geq 140 \mathrm{mmHg}$ and/ or $\mathrm{DBP} \geq 90 \mathrm{mmHg}$. Twenty four $(40 \%)$ subjects were normotensive. Insulin resistance was found in $30(50.0 \%)$ subjects. Table 1 shows the general description of the study subjects' characteristics.

Figure.1 shows the comparison of BMP-2 plasma concentrations in normotensive versus hypertensive subjects and Table 2 shows significant higher level of BMP-2 in the hypertension group using Mann-Whitney U Analysis ( $\mathrm{p}=0.008)$.

Spearman bivariate analysis showed a positive significant correlation between hypertension and BMP-2 ( $\mathrm{r}$ $=0.345, \mathrm{p}=0.007)$, further age stratification analysis was done with the cut off point of 55 years of age (Table.3) and showed the correlation between hypertension and BMP-2 was stronger $(r=0.436, p=0.016)$ in younger subjects (age less than 55 years old).

Insulin sensitivity had a strong effect on hypertension, yet the positive correlation between hypertension and BMP-2 remained significant $(r=0.374, \mathrm{p}<0.05)$ after HOMA IR, as insulin resistance index, being controlled by Spearman partial correlation analysis. However, the correlation was stronger in subjects with insulin resistance $(r=0.404, p=0.027)$ as shown in Table 4 using stratification analysis. 


\section{Table 1. Description of the Study Subjects' Characteristics}

\begin{tabular}{llrrrr}
\hline Subjects' Characteristics & Unit & Min & $\begin{array}{r}\text { Max } \\
\mathbf{N}=\mathbf{6 0}\end{array}$ & Median & $\begin{array}{c}\text { Mean } \pm \text { SD } \\
\text { Description }\end{array}$ \\
\hline Age & year & 45.0 & 70.0 & 55.0 & $55.2 \pm 6.5$ \\
Smoking & - & - & - & - & $15.0 \%$ \\
Regular exercise & - & - & - & - & $56.7 \%$ \\
Hypertension & - & - & - & - & $50.0 \%$ \\
R/ antihypertension & - & - & - & - & $41.7 \%$ \\
Insulin Resistance & - & - & - & - & $50.0 \%$ \\
Height & $\mathrm{cm}$ & 155.0 & 180.0 & 167.0 & $167.0 \pm 5.9$ \\
Weight & $\mathrm{kg}$ & 62.0 & 112.0 & 80.0 & $80.3 \pm 10.8$ \\
BMI & $\mathrm{kg} / \mathrm{m}^{2}$ & 23.2 & 37.5 & 28.1 & $28.8 \pm 3.3$ \\
Waist circumference & $\mathrm{cm}$ & 90.0 & 125.0 & 99.0 & $101.0 \pm 7.9$ \\
SBP & $\mathrm{mmHg}$ & 100.0 & 183.0 & 130.0 & $129.3 \pm 14.8$ \\
DBP & $\mathrm{mmHg}$ & 60.0 & 100.0 & 80.0 & $82.0 \pm 8.6$ \\
Fasting Plasma Glucose & $\mathrm{mg} / \mathrm{dL}$ & 81.0 & 123.0 & 98.0 & $99.4 \pm 10.5$ \\
HOMA IR & - & 0.5 & 6.4 & 2.7 & $2.9 \pm 1.5$ \\
hsCRP & $\mathrm{mg} / \mathrm{dL}$ & 0.2 & 9.6 & 1.5 & $2.3 \pm 2.1$ \\
BMP-2 & $\mathrm{pg} / \mathrm{mL}$ & 142.0 & 4095.0 & 1796.0 & $1736.6 \pm 1015.7$ \\
& & & & & \\
\hline
\end{tabular}

${ }^{*} \mathrm{R} /=$ on treatment; $\mathrm{BMI}=$ Body Mass Index; $\mathrm{SBP}=$ Systolic Blood Pressure; $\mathrm{DBP}=$ Diastolic Blood Pressure; HOMA-IR $=$ Homeostasis Model Assessment of Insulin Resistance; hsCRP = High sensitivity C-reactive Protein; BMP-2 = Bone Morphogenetic Protein-2

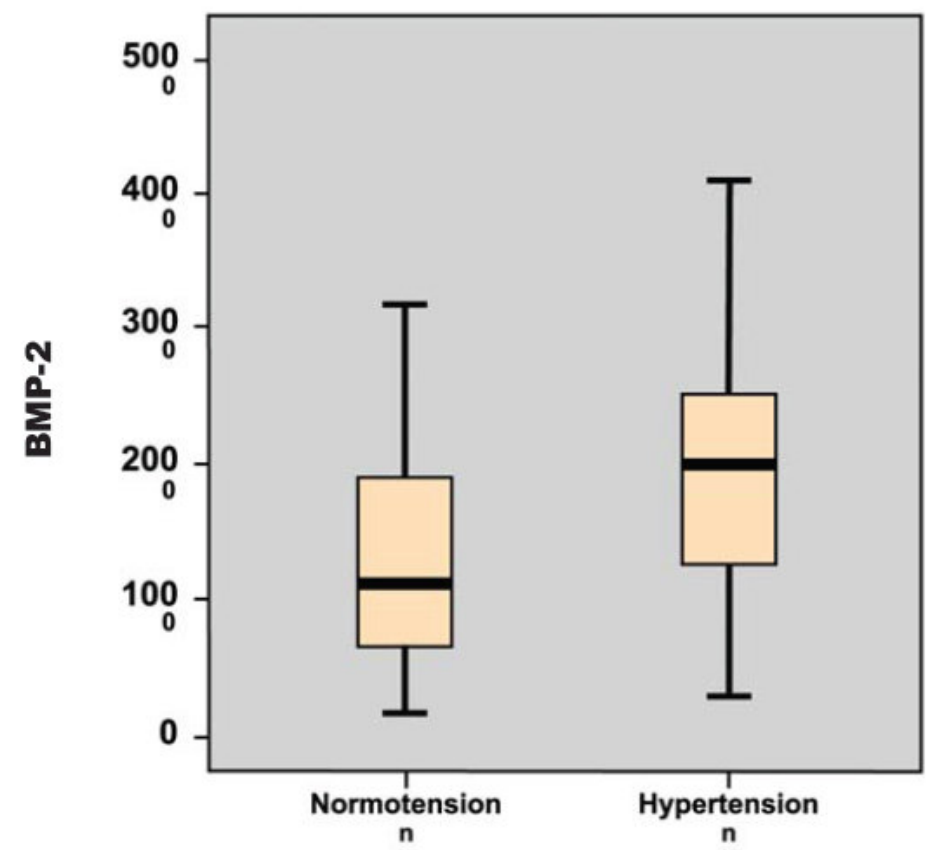

Figure 1. Comparison of BMP-2 in hypertension and normotension subjects 


\section{Table 2. Comparison of BMP-2 levels in Normotension and Hypertension using Mann-Whitney U Analysis}

\begin{tabular}{lcccc}
\hline BMP2 $(\mathrm{pg} / \mathrm{mL})$ & $\mathbf{n}$ & Median $(\min -\mathrm{max})$ & Mean $\pm \mathrm{SD}$ & p-value \\
\hline Normotension & 24 & $1109(142-3161)$ & $1330.5 \pm 828.2$ & 0.008 \\
Hypertension & 36 & $1979(292-4095)$ & $2007.3 \pm 982.4$ & \\
\hline
\end{tabular}

* significant value at $p<0.05$

Table 3. Stratification analysis of age with cut off point of 55 years of age

\begin{tabular}{|c|c|c|c|c|c|c|}
\hline & \multicolumn{6}{|c|}{ BMP-2 } \\
\hline & \multicolumn{2}{|c|}{ Age $<55$ year old $(n=30)$} & \multicolumn{2}{|c|}{ Age $\geq 55$ year old $(n=30)$} & \multicolumn{2}{|c|}{ Total subjects $(n=60)$} \\
\hline & $\mathbf{r}$ & $\mathbf{p}$ & $\mathbf{r}$ & $\mathbf{p}$ & $\mathbf{r}$ & p \\
\hline Hypertension & $0.436 *$ & 0.016 & 0.151 & 0.427 & $0.345^{* *}$ & 0.007 \\
\hline
\end{tabular}

${ }^{\star}$ significant value at $p<0.05 ;{ }^{\star *}$ significant at $p<0.01$

Table 4. Stratification analysis of HOMA-IR with cut off value of 2.70

\begin{tabular}{ccccccc}
\hline & \multicolumn{4}{c}{ Insulin sensitive $(\mathbf{n = 3 0})$} & \multicolumn{2}{c}{ BMP-2 } \\
& $\mathbf{r}$ & $\mathbf{p}$ & $\mathbf{r}$ & $\mathbf{p}$ & $\mathbf{r}$ & $\mathbf{p}$ \\
\hline Hypertension & 0.295 & 0.113 & $0.404^{*}$ & 0.027 & $0.345^{* *}$ & 0.007 \\
\hline
\end{tabular}

* significant value at $p<0.05 ;{ }^{*}$ significant at $p<0.01$

\section{Discussion}

This study aimed to determine the relationship between hypertension with BMP-2 in central-obese non-diabetic men with evidence of coronary calcification.

We found that BMP-2 plasma concentration was significantly higher in the hypertensive subjects compared with the normotensive subjects, and there was a positive significant correlation between hypertension and BMP-2. These findings are in line with the previous studies, suggesting that high blood pressure not only induces the expression of BMP-2 in endothelial cells $(10,12,15)$ but may also be associated with the increasing plasma concentration of BMP-2. This finding may in part explain the pathomechanism of hypertension with coronary artery calcification.

Csiszar et al have proposed that vascular BMP-2 expression can be regulated by $\mathrm{H}_{2} \mathrm{O}_{2}$-mediated activation of of NF-kB both by inflammatory stimuli and by high intravascular pressure. The proinflammatory cytokine tumor necrosis factor TNF- $\alpha$ induced of NF-kB activation and elicited significant increases in BMP-2 mRNA and protein in primary coronary arterial endothelial cells (CAECs) and human umbilical vein endothelial cells (HUVECs) that were prevented by of NF-kB inhibitors (pyrrolidine dithiocarbamate and $\mathrm{SN}-50$ ), silencing of $\mathrm{p} 65$ (siRNA), or catalase. Administration of $\mathrm{H}_{2} \mathrm{O}_{2}$ also elicited of NF-kB activation and BMP-2 induction. In organ 
culture, exposure of rat arteries to high pressure (160 $\mathrm{mm} \mathrm{Hg}$ ) elicited $\mathrm{H}_{2} \mathrm{O}_{2}$ production, nuclear translocation of of NF-kB, and upregulation of BMP-2 expression. Although high pressure upregulated ofNF-kB, it appears that it directly regulates BMP-2 expression, because upregulation of BMP-2 was also observed in vessels of of NF-kB knockout mice (12).

Interestingly, BMP-2 itself can elicit oxidative stress in endothelial cells and promote vasodilator dysfunction by stimulating superoxide production and inflammatory responses in endothelial cells, raising the possibility that proinflammatory effects of BMPs-2 may play a role in vascular diseases such as hypertension and atherosclerosis (15).

Many lines of evidence thus suggest that BMPs may function as proinflammatory, prohypertensive, and proatherogenic mediators in the vessel wall (10).

This correlation between hypertension and BMP- 2 was stronger in young subjects, indicating the possible pathomechanism differences of coronary artery calcification build-up between younger and older population. Sweatt et al. reported that immunohistochemistry of calcified lesions in the aortic wall of aging rats contained elevated concentrations of Glu-MGP that was poorly gammacarboxylated and did not bind BMP-2. The vitamin $\mathrm{K}$-dependent protein, matrix Gla protein (MGP), is a binding protein for BMP-2. The $\mathrm{Ca}^{2+}$-induced conformer of the vitamin $\mathrm{K}$-dependent Gla region in MGP is involved in BMP-2 binding. Recombinant BMP-2 binds to the Glacontaining region of MGP in the presence of $\mathrm{Ca}^{2+}$. Agerelated arterial calcification may be a consequence of under-gamma-carboxylation of MGP, allowing unopposed BMP-2 activity (16)

Due to its good correlation to glycemic clamp, HOMA-IR has been widely utilized as insulin resistance index in clinical and epidemiological studies, HOMA-IR is calculated according to the formula: fasting insulin $(\mu \mathrm{U} / \mathrm{L})$ $\mathrm{x}$ fasting glucose $(\mathrm{nmol} / \mathrm{L}) / 22.5$. There is no standard value for HOMA-IR. Several studies consider that HOMA-IR $\geq 2.77$ is an indicator of insulin resistance (17), yet the cutoff points of HOMA-IR differ among races. Therefore, in this study, we used the median of the subject's HOMAIR value (2.70) as a cutoff point to differentiate insulin sensitive and insulin resistance subjects.

The Spearman partial correlation analysis showed that the correlation of hypertension and BMP-2 was effected by insulin resistance state, yet after the insulin resistance was controlled, the correlation remained significant. However, further stratification analysis showed that the correlation was stronger in subjects with insulin resistance. These findings may partly be explained by the study of
Zhang et al. in which they proposed the cross talk between insulin and bone morphogenetic protein signaling systems (18). Hirose et al. conducted a seven-year follow up study on 310 middle-aged Japanese men (The KEIO Study) on the effect of insulin resistance on hypertension and found that both SBP and DBP were positively correlated with HOMA-IR and suggested the important role of insulin resistance in predicting the future incidence of hypertension (19). The mechanisms of the association of insulin resistance with the development of hypertension are not fully understood. Animal studies have suggested: 1) increased sodium retention due to hyperinsulinemia, 2) sympathetic nervous system activation, and 3) endothelial dysfunction (decreased production of nitric oxide, etc.) due to insufficient action of insulin are related (20).

\section{Conclusions}

There is a significant positive correlation between hypertension and BMP-2 in central-obese non-diabetic men with evidence of coronary artery calcification, which remains significant after insulin resistance being controlled. BMP-2 plasma concentration is significantly higher in the hypertension subjects compared to normotensive subjects.

\section{Acknowledgement:}

Authros express the greatest gratitude to staff of radiology and laboratory departement of Siloam hospital Lippo village, staff of Prodia clinical laboratory, teachers of Doctoral program, Medical faculty of Hasanuddin university and Pelita Harapan university, for research and scientific support.

\section{References:}

1. Schauer IE, Snell-Bergeon JK, Bergman BC, Maahs DM, Kretowski A, Eckel RH, et al. Insulin resistance, defective insulin-mediated fatty acid suppression, and coronary artery calcification in subjects with and without type 1 diabetes: The CACTI study. Diabetes. 2011; 60: 306-14.

2. Chahwala V, Arora R. Cardiovascular manifestations of insulin resistance. Am J Ther. 2009; 16: e14-28.

3. Derwall M, Malhotra R, Lai CS, Beppu Y, Aikawa E, Seehra JS, et al. Inhibition of Bone Morphogenetic Protein Signaling Reduces Vascular Calcification and Atherosclerosis. Arterioscler Thromb Vasc Biol. 2012; 32: 613-22

4. Rodrigues TC, Veyna AM, Haarhues MD, Kinney GL, Rewers $\mathrm{M}$, Snell-Bergeon JK. Obesity and coronary artery calcium 
in diabetes: the Coronary Artery Calcification in Type 1 Diabetes (CACTI) study. Diabetes Technol Ther. 2011; 13: 991-6.

5. Jamjoum LS, Bielak LF, Turner ST, Sheedy IP, Boerwinkle E, Raghunathan TE, et al. Relationship of blood pressure measures with coronary artery calcification. Med Sci Monit. 2002; 8: CR775-81.

6. Mayer B, Lieb W, Radke PW, Gotz A, Fischer M, Bassler A, et al. Association between arterial pressure and coronary artery calcification. J Hypertens. 2007; 25: 1731-8.

7. Rodrigues TC, Canani LH, Schvartzman P, Gross JL. Hypertension is the metabolic syndrome component most strongly associated with microvascular complications and coronary artery calcification in Type 1 diabetes. J Endocrinol Invest. 2011; 34: e58-63.

8. McEniery $\mathrm{CM}$, McDonnell BJ, So A, Aitken S, Bolton CE, Munnery $\mathrm{M}$, et al. Aortic calcification is associated with aortic stiffness and isolated systolic hypertension in healthy individuals. Hypertension. 2009; 53: 524-31.

9. Jensky NE, Criqui MH, Wright MC, Wassel CL, Brody SA, Allison MA. Blood pressure and vascular calcification. Hypertension. 2010; 55: 990-7.

10. Csiszar A, Lehoux S, Ungvari Z. Hemodynamic forces, vascular oxidative stress, and regulation of BMP-2/4 expression. Antioxid Redox Signal. 2009; 11: 1683-97.

11. Zhang M, Zhou SH, Zhao SP, Liu QM, Li XP, Shen XQ. Irbesartan attenuates Ang II-induced BMP-2 expression in human umbilical vein endothelial cells. Vasc Med. 2008; 13 : 239-45.

12. Csiszar A, Smith KE, Koller A, Kaley G, Edwards JG, Ungvari Z. Regulation of bone morphogenetic protein-2 expression in endothelial cells: role of nuclear factor-kappaB activation by tumor necrosis factor-alpha, $\mathrm{H} 2 \mathrm{O} 2$, and high intravascular pressure. Circulation. 2005; 111: 2364-72.
13. Raggi $P$, Gongora MC, Gopal A, Callister TQ, Budoff M, Shaw LJ. Coronary artery calcium to predict all-cause mortality in elderly men and women. J Am Coll Cardiol. 2008; 52: 1723.

14. Shaw LJ, Raggi P, Schisterman E, Berman DS, Callister TQ. Prognostic value of cardiac risk factors and coronary artery calcium screening for all-cause mortality. Radiology. 2003; 228: 826-33.

15. Csiszar A, Ahmad M, Smith KE, Labinskyy N, Gao Q, Kaley G, et al. Bone morphogenetic protein-2 induces proinflammatory endothelial phenotype. Am J Pathol. 2006; 168: 629-38.

16. Sweatt A, Sane DC, Hutson SM, Wallin R. Matrix Gla protein (MGP) and bone morphogenetic protein-2 in aortic calcified lesions of aging rats. J Thromb Haemost. 2003; 1: 178-85.

17. Meier U, Gressner AM. Endocrine regulation of energy metabolism: review of pathobiochemical and clinical chemical aspects of leptin, ghrelin, adiponectin, and resistin. Clin Chem. 2004; 50: 1511-25.

18. Zhang $H$, Schulz TJ, Espinoza DO, Huang TL, Emanuell $\mathrm{B}$, Kristiansen $\mathrm{K}$, et al. Cross talk between insulin and bone morphogenetic protein signaling systems in brown adipogenesis. Mol Cell Biol. 2010; 30: 4224-33.

19. Hirose H, Saito I, Kawabe H, Saruta T. Insulin resistance and hypertension: seven-year follow-up study in middle-aged Japanese men (the KEIO study). Hypertens Res. 2003; 26: 795-800.

20. Anderson EA, Mark AL. The vasodilator action of insulin. Implications for the insulin hypothesis of hypertension. Hypertension. 1993; 21: 136-41. 